\title{
Damage and loss prediction model considering inundation level, flow velocity and vulnerability of building types
}

\author{
H. Maiwald \& J. Schwarz \\ Earthquake Damage Analysis Center (EDAC), \\ Bauhaus Universität Weimar, Germany
}

\begin{abstract}
Reliable prognoses of building damage caused by flood impact require realistic relationships between action and damage or loss describing parameters. Due to the fact that commonly applied damage functions are related to the different usage classes (i.e. private housing), the required differentiation according to the parameters on the resistance side is still missing and further impact parameters like flow velocity remain unconsidered. On the basis of the Earthquake Damage Analysis Center (EDAC) flood database (including different datasets collected after the 2002 flood in Saxony), a method to determine the structural damage and the losses for any given flood scenario was developed. The key elements of the developed method are the engineered evaluation and categorization of the existing building stock, the definition of five damage grades with respect to the observed damage patterns and the classification of building types into vulnerability classes (and the consideration of the inherent scatter). Specific Functions enabling the calculation of damage grades and the loss assessment in separate steps of the same procedure. Specific Vulnerability Functions (SVF) are related to the inundation level or additionally the flow velocity (action side), and the predominant building types or the vulnerability classes (resistance side). Specific Damage Functions (SDF) can calculate the expected losses directly under consideration of the inundation level and the predominant building types (SDF of Type 1a) or the assigned vulnerability classes (SDF of Type 1b). SDF of Type 2 transfers the damage grades into loss statements. The developed tools are applied to the reinterpretation of the August 2002 flood damage. Results are presented for different study areas on a micro-scale level. In all cases, remarkably good agreement between the predicted and the reported losses can be
\end{abstract}


stated. First investigations with respect to the location of buildings, the direction of flow and the structural damage are also represented.

Keywords: damage grades, flood damage, damage functions, flow velocity, loss estimation, specific energy height, vulnerability classes, vulnerability functions.

\section{Introduction}

Estimating damage caused by flood impact is an important, yet scientifically and methodically insufficiently investigated task. The large scatter within the scarcely available damage data as well as the remarkable diversity (in shape and amplitude characteristics) of the statistically derived damage functions contribute to uncertain and often misleading loss predictions. The situation is still more complicated as harmonized damage assessment procedures and documentation manuals are missing.

This paper refers to the development of a damage and loss prediction model based on an engineering evaluation system of buildings [1, 2]. Alluding to the procedure developed in the risk analysis of earthquakes, it is checked, whether methodical fundamentals can be transferred or have to be adopted, and which parameters must be derived from data surveys. As an essential improvement, in addition to the inundation level, the flow velocity on the action side $[3,4]$ and the impact of structural parameters on the resistance side $[5,6]$ are considered.

Preliminary results of the approach are concentrated on the case studies of the towns Eilenburg, Döbeln and Grimma, being particularly affected by the 2002 flood in Saxony (Eastern Germany). Innovative damage and loss assessment procedures are developed including the unified definition of global structural Damage Grades $\left(\mathrm{D}_{\mathrm{i}}\right)$ and Specific Vulnerability Functions (SVF), Specific Damage Functions (SDF) being related to the damage and loss or the specific flood vulnerability classes (HW-VC) of a building or object. As is it can be shown, the tools enable the reinterpretation of damage with respect to structural and loss parameters, and are, therefore, suited for prognoses purposes and shortand long term disaster management decisions.

\section{Data base}

The key element of the procedure lies in the preparation of the real damage cases, which were elaborated immediately after the 2002 floods in Saxony.

- Dataset 1 is related to the outcome of a questionnaire survey performed by the authors between 2002 and 2004 [5].

- Dataset 2 is the outcome of telephone calls after the 2005 Danube flood in Bavaria and 2006 Elbe flood in Saxony (performed within the frame of the RIMAX project MEDIS [7]).

- Dataset 3 is the outcome of an evaluation of damage expertises by order of the "Landestalsperrenverwaltung Sachsen (LTV)" [8].

After having unified the data with respect to the structural parameters and having transferred the verbal damage descriptions into the proposed scheme of 
damage grades, the datasets could be considered separately and as a combination. The datasets include information about duration, velocity (qualitatively) and other secondary (probably damage contributing) flood action as well as vulnerability-related parameters. Dataset 1 and 2 are quite complementary with respect to parameter ranges of inherent data points, and lead to a well distributed database. Dataset 3 is the outcome of an evaluation of qualified damage expertises and is therefore considered separately in the following investigations.

Nevertheless, due to the differences within, the derived vulnerability functions have an impact on the prognosis results (see Figure 1).

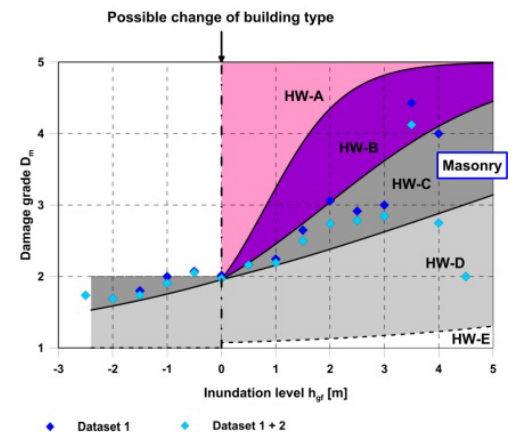

a) State $2008[4]$

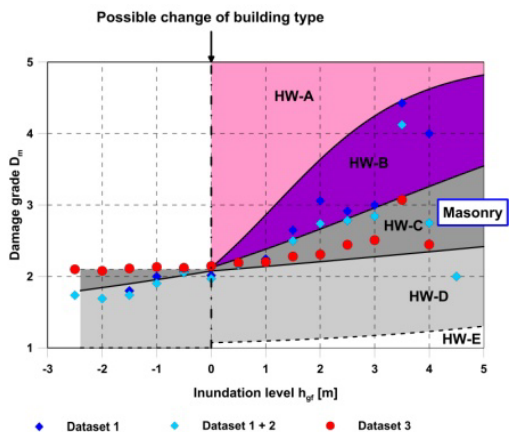

b) State 2012

Figure 1: Damage grades, inundation level and vulnerability classes; results for masonry buildings.

\section{Basic elements of the flood damage and loss prediction model}

During the last years, and as outcomes of practical requests, several research projects of the EDAC have been concentrated on the development of an engineering evaluation system of buildings subjected to natural hazards and the elaboration of more refined tools to link elements of hazard, action, vulnerability, damage and loss in a modular way $[1,2,4]$. The procedures and the processing levels implemented in the model are structured transparently and can be used for different risk types (earthquake, storm, flood, tsunami etc.).

Basics steps of the procedure are derived from analogous considerations to the empirical, intensity-oriented method introduced for the earthquake damage and loss model on the basis of EMS-98 [9].

Mainly focusing the consideration on structural damage due to flood impact, characteristic vulnerability classes are determined for the different building types. Their vulnerability functions are derived by the following step-by-step procedure. 


\subsection{Damage descriptions and assignment of repeatedly observed effects}

Field surveys have to be qualified with respect to the documentation of damage cases and the collection of structural parameters affecting the vulnerability of each building. The documentation has to implement an "engineered" description of the building and its structural damage, and to archive typical damage patterns. Repeatedly observed effects are used as indicators for the definition of damage grades. In addition to the structural damage, observed damage-indicating phenomena can be related to chemical or physical origin [6]. For the damage classification, rehabilitation measures are of importance to convert the visible action or technological term into a generalized scheme of damage interpretation. Table 1 summarizes the main criteria for the classification of observed effects and damage reports, in an extended and widely applicable format.

Table 1: $\quad$ Assignment of damage grades $\mathrm{D}_{\mathrm{i}}$ to damage cases $[4,6]$.

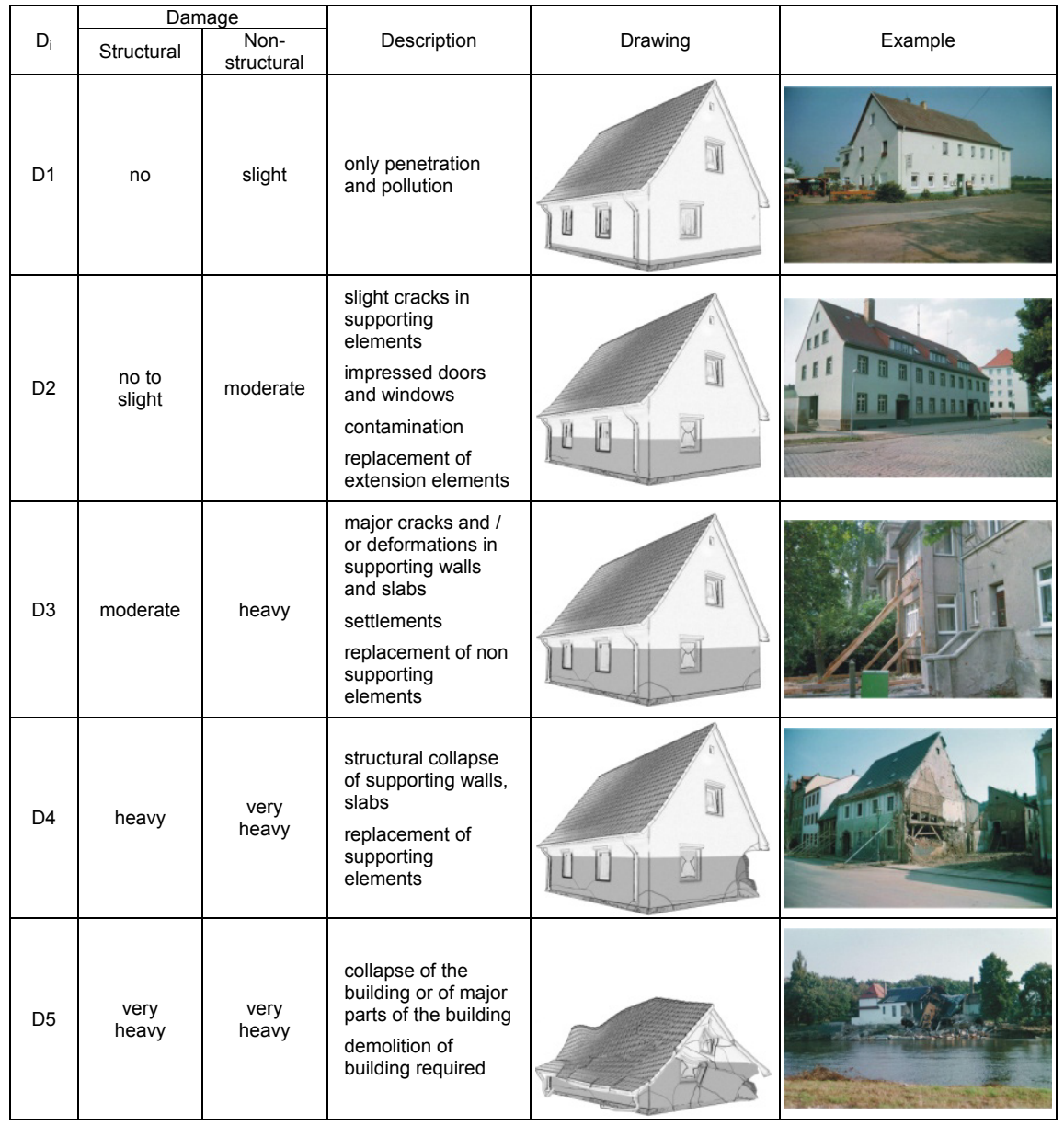




\subsection{Definition of damage grades}

Repeatedly observed effects can be regarded as typical building response indicators for a comparable level of damage, loss of integrity, stability etc.

Table 1 provides the background for the necessary generalization of any damage classification. By the definition of damage grades $\left(\mathrm{D}_{\mathrm{i}}\right)$, a unified evaluation of all damage data and reports is guaranteed. Damage grades enable the logical link between flood impact and loss in an innovative way. In all cases a minimum damage grade D1 (without the occurrence of structural damage) has to be assigned due to humidity penetration effects. The generalized damage definitions are related to the quality of structural damage and non-structural damage as well as to the required extent of rehabilitation or other damage replacement measures (cf. Table 1).

\subsection{Correlation between flood impact parameters and building damage $\left(\mathrm{D}_{\mathrm{i}}\right)$}

In the majority of cases, the damage descriptions submitted by the questionnaires (dataset 1), telephone calls (dataset 2) or the expertises (dataset 3) have to be translated into damage grades. This essential work has been performed by engineers from EDAC staff on the basis of the developed evaluation tools (Table 1). For each damage case, the damage grade $D_{i}(i=1$ to 5$)$ and the flood action parameters could be assigned. On the basis of sample individual damage grades (i.e. for the same building type under comparable inundation heights), the mean damage grade $\left(D_{m}\right)$ can be determined, which is a robust parameter for damage prognosis (see Figure 1).

The level of the ground floor is taken as a reference height for the flood impact $\left(\mathrm{h}_{\mathrm{gf}}\right)$. By this definition of inundation height, it is recognized that at this level an abrupt change of building material and/or structural systems (basement to ground floor) and, consequently, of vulnerability might occur. Therefore, in the vicinity of $h_{g f}=0$, discontinuities in the vulnerability function curve indicate the new quality of the approach, i.e., vulnerability classes of basement and other building floors have to be assigned separately (see Figure 1).

For the all masonry buildings included in the datasets, mean damage grades $D_{m}$ are calculated for intervals of inundation height $(\Delta h)$. Results of this procedure are illustrated for the predominant building type (masonry wall structures). Taking for the interval of inundation height $\Delta \mathrm{h}=0.5 \mathrm{~m}$, the increase of mean damage grade $\left(\mathrm{D}_{\mathrm{m}}\right)$ with the impact parameter becomes evident. The dots derived from the basic datasets of this study create the new type of damage functions. Figure 1a shows the outcome of the investigations in [4, 6]. As a result of the consideration of the more qualified dataset 3, the borderlines for the vulnerability classes have to be adjusted (Figure 1b). Further investigations are necessary.

\subsection{Ranges of vulnerability classes for the predominant building types}

For each building, the characteristic building type (or structural system) and its vulnerability class have to be identified. "Vulnerability" is taken as a measure for 
the resistance of a building against comparable impact conditions (inundation height, flow velocity) and is related to the differences in the damage (or loss) under these action parameters. Vulnerability functions are expressions of the existing correlations. Their quality can be improved by assigning the typical ranges and the scatter for the regionally predominant building types. Buildings of different structural type and material belong to the same vulnerability class, if for the relevant range of flood action parameter, similar mean damage grades have to be expected (Table 1). Due to the uniform quality of the database, it was possible to identify typical shapes of (still idealized) vulnerability describing functions (see Figure 1).

As a whole, five Flood Vulnerability Classes (here: HW-A to HW-E) are distinguished by definition, covering the range from low flood resistance/higher vulnerability (A - very sensitive; B - sensitive), to normal (C) and increased flood resistance (D).

Hypothetically, a flood resistant design (FRD) would lead to class (HW-E). Class HW-E buildings (as recommended in common guidelines) are characterized by a separation of building from the flood water table, for instance, by "up-lifting" the base floor over a grid of story-high columns. To convert each building of the dataset into its vulnerability class, a classification scheme is required, which takes into account the data density as well as the scatter within the representative samples of each building type (see Table 2).

For each building the characteristic structural system (here denoted as building type) has to be identified. Subsequently, the building types have to be sorted into their appropriate vulnerability classes, where most likely, still probable and also exceptional cases have to be considered (Table 2). The symbols in Table 2 replace empirical vulnerability functions in a robust way. The lines (full, broken) indicate the range of scatter and the probability of occurrence.

The vulnerability of building types can cover ranges of two or three vulnerability classes. If the user of the scheme is untrained in engineering practice or cannot decide about the extent of vulnerability affecting particularities (due the lack of information), the most likely vulnerability has to be taken.

\subsection{Specific Vulnerability Functions (SVF)}

\subsubsection{Correlation between damage grade $D_{i}$ and inundation level $h_{g f}$}

The innovative elements of the whole procedure can be subsumed and linked by a new type of (SVF), systematically developed and continuously presented depending on the progress of data elaboration $[5,6,10]$. The database enables the differentiation of these functions with respect to the main structural (wall) material (SVF type 1a) or, alternatively, with respect to the flood vulnerability class (SVF type 1b). Examples for the latter, reflecting the outcome of the combined dataset $1+2$, can be taken from Figure 2a [2]. Figure $2 \mathrm{~b}$ shows the results derived from the more comprehensive dataset 3 . 
Table 2: Classification of building types in vulnerability classes and identification of ranges of scatter (on the basis of the evaluated data).

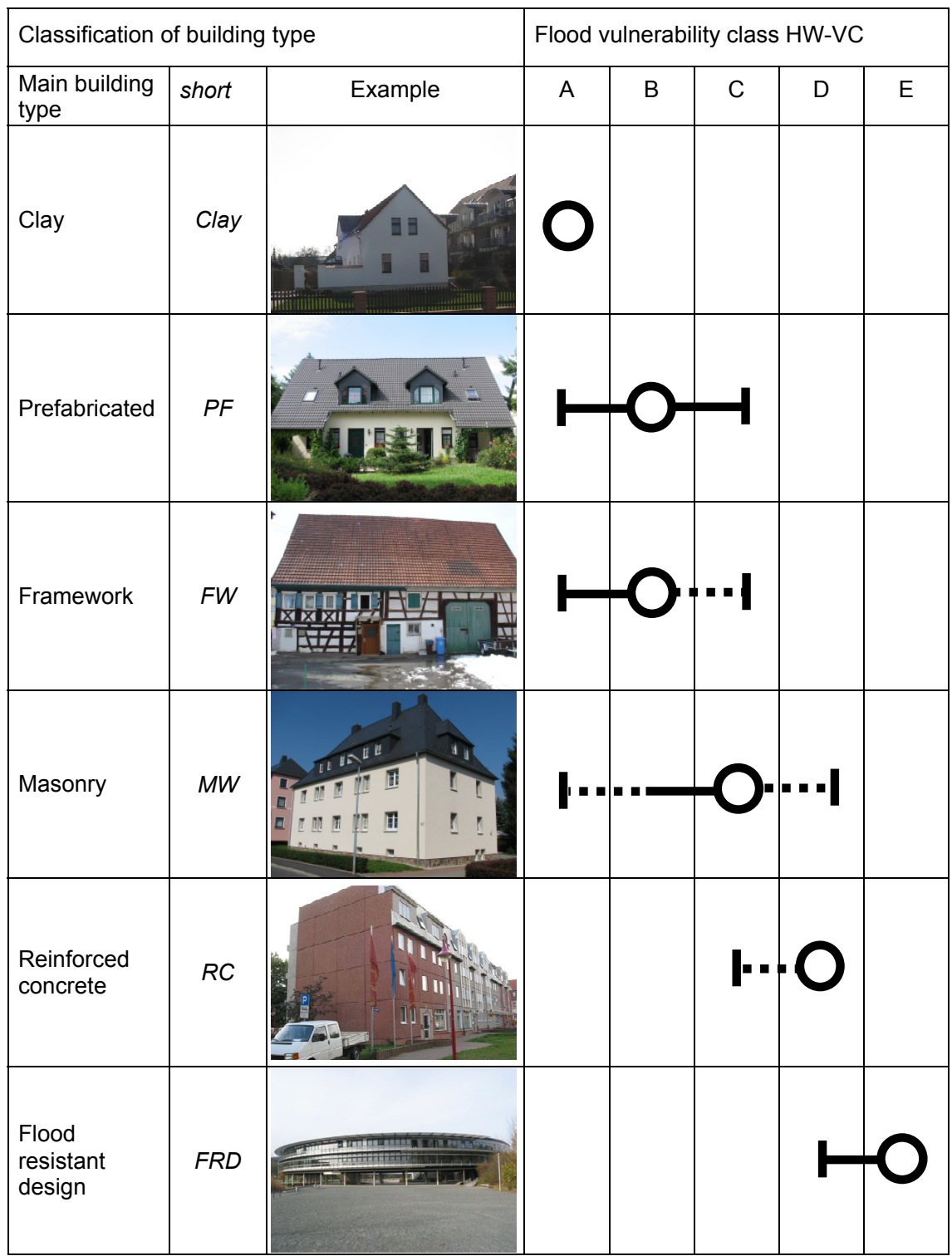

Most likely vulnerability class

- Probable range

... Range of less probable, exceptional cases 


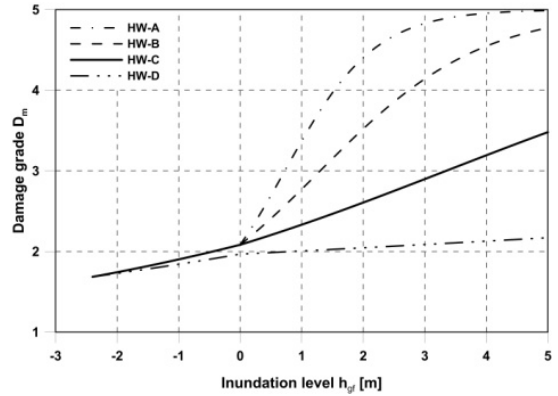

a) SVF type $1 \mathrm{~b}$ : Dataset $1+2$

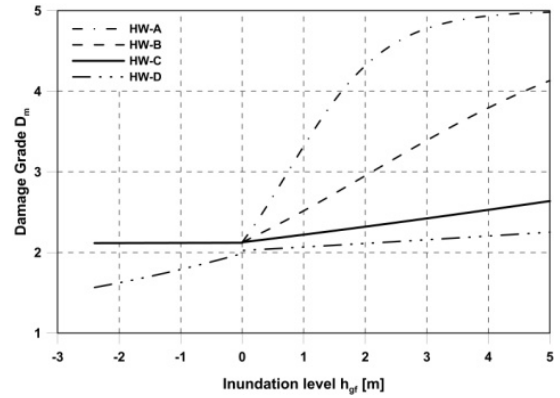

b) SVF type 1b: Dataset 3

Figure 2: $\quad$ Specific vulnerability functions of type: $D_{m}=f\left(h_{g f}\right)$.

\subsubsection{Correlation between damage grade $D_{i}$ and the specific energy height}

A first outcome within the framework of the RIMAX-project "MEDIS" for consideration of flow velocity was presented in [4].

For a few of the flooded areas in the 2002 event in Saxony, information about the recalculated flow velocity $\left(\mathrm{v}_{\mathrm{fl}}\right)$ was submitted by the Regulatory Office (LTV).

It has to be highlighted that for a rather limited number of damage cases the relevance of flood velocity $\left(\mathrm{v}_{\mathrm{fl}}\right)$ in combination with the inundation level above ground level $\left(\mathrm{h}_{\mathrm{gl}}\right)$ could be investigated. The first approach related to flood intensity $\left(\mathrm{h}_{\mathrm{gl}} \times \mathrm{v}_{\mathrm{fl}}\right)$ failed because no clear tendency could be established [1]. In a second approach, the specific energy height $\mathrm{H}=\mathrm{h}_{\mathrm{gl}}+\left(\mathrm{v}_{\mathrm{fl}}{ }^{2} / 2 \mathrm{~g}\right)$ is predicted. Due to the limited number of samples, the building stock remains undifferentiated (being representative for masonry buildings). As a result of this first data check, a building material independent vulnerability function (SVF type $2^{*}$ ) is given by Figure 3a.

It can be concluded that mean damage grade $\mathrm{D}_{\mathrm{m}}$ remains nearly constant for $\mathrm{H}<2.0 \mathrm{~m}$; for $\mathrm{H}>2.0 \mathrm{~m}$, a steady increase of damage grade can be derived from the observations, which is mainly attributed to the impact of increasing flow velocity $\left(\mathrm{v}_{\mathrm{fl}}\right)$. From an engineering point of view, this clear tendency seems to be explainable.

Further investigations in the same flooded areas, but with a larger number of damage cases (taken from dataset 3), are published in [3]. Figure 3b shows preliminary vulnerability functions for vulnerability classes (SVF type 2b). Due to the still relatively low data volume for the vulnerability class $\mathrm{HW}-\mathrm{A}$, the corresponding vulnerability function is still an engineering-based assumption.

The starting values for the damage grades $\mathrm{D}_{\mathrm{m}}$ at $\mathrm{H}=0 \mathrm{~m}$ results from flooding in the basement area, because about $80 \%$ of the examined damage data regarding structures with basements. 


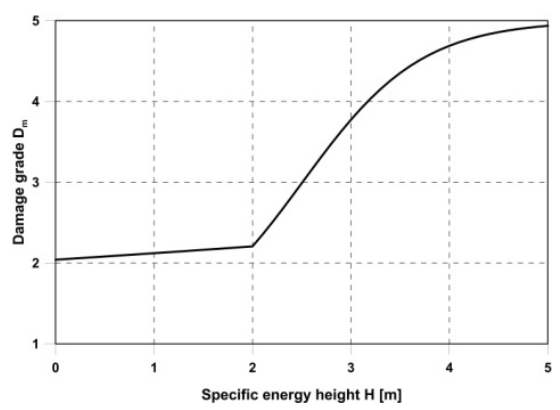

a) SVF type $2 *$ : Dataset 1 [4]

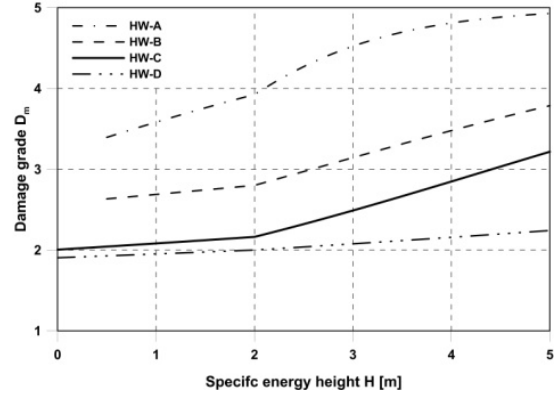

b) SVF type 2b: Dataset 3 [3]

Figure 3: $\quad$ Specific vulnerability functions of type: $\mathrm{D}_{\mathrm{m}}=\mathrm{f}\left(\mathrm{h}_{\mathrm{gl}}, \mathrm{v}_{\mathrm{fl}}\right)$.

The vulnerability classes HW-A and HW-B are generally not found in the basement area. Therefore, the corresponding vulnerability functions in Figure $3 \mathrm{~b}$ are shown only for a specific energy height level of $\mathrm{H}>0.5 \mathrm{~m}$. The characterization of the qualitative features of the functions for $\mathrm{H}<0.5 \mathrm{~m}$ remains to be determined by further investigations on a larger dataset. Further research is required to establish damage prediction models in zones where a sudden increase of flow velocity is expected due to the hydrological and topographical situation.

The parameters for the different types of vulnerability functions (with exception of the functions in Figure 2b) could be taken from [2] .

\subsection{Location Specific Vulnerability Functions (LSVF)}

The location of the structure relative to the flow velocity vector (flow direction) and the urban-structural integration of the structure have an influence on the structural damage. Table 3 shows a preliminary proposal for the classification of the relevant situations from an engineering point of view on the classification of a building into the surrounding housing and the flow characteristic during flood events [3]. Real structures of settlement are usually complex; therefore, a simplified classification scheme does not cover all situations. For example, if the flow directions change during a flood event. Buildings are also often not orthogonal and tangential to the incident flow direction, so that a classification according to Table 3 is clearly not possible. In addition, the flow direction can be set for complex site conditions only by specifying a velocity vector. The classification scheme in Table 3 is therefore to be understood as a first proposal and has to be revised on a larger database.

Figure 5 shows an attempt to classify different situations from the real development study areas, assuming a main flow direction according to the scheme in Table 3. Analogous to the procedure in 3.3, the mean damage grades $\mathrm{D}_{\mathrm{m}}$ are calculated at intervals of $\Delta \mathrm{H}=0.5 \mathrm{~m}$. 
62 Flood Recovery Innovation and Response XI

Table 3: Classification scheme with respect to the location of buildings and flow direction (cf. [3])

\begin{tabular}{|c|c|c|c|}
\hline Nr. & Type/Location & Description & Flow direction \\
\hline 1 & Stand alone & & Directly \\
\hline $2 a$ & Front house & Beginning of a row of houses & Directly / flow around \\
\hline $2 \mathrm{~b}$ & End house & End of a row of houses & Flow around / circulation \\
\hline $2 \mathrm{c}$ & Front/ End house & Beginning / end of a row of houses & Orthogonally/ circulation \\
\hline $3 a$ & Central house & In the middle of a row of houses & Tangentially \\
\hline $3 b$ & Central house & In the middle of a row of houses & Directly / orthogonally \\
\hline 4 & Corner house & Cross situation & Flow around / circulation \\
\hline
\end{tabular}

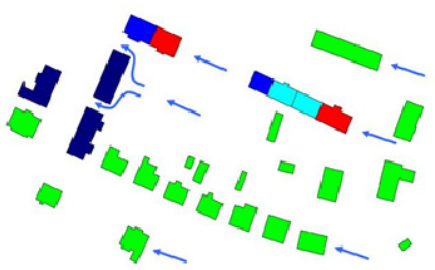

a) Single house and row

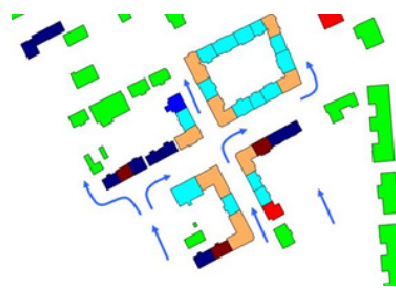

c) Mixed structures

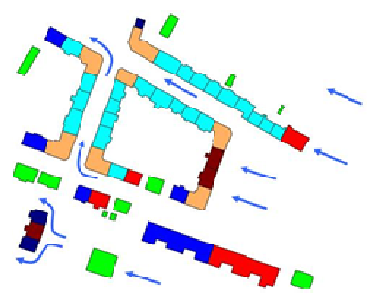

b) Block and row

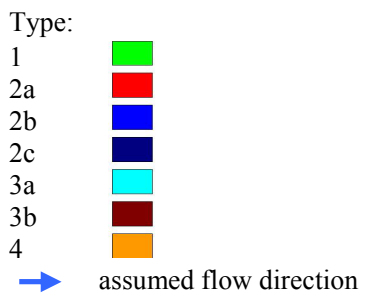

d) Single house and row

Figure 4: Examples for classification of real structure of settlement (Table 3).

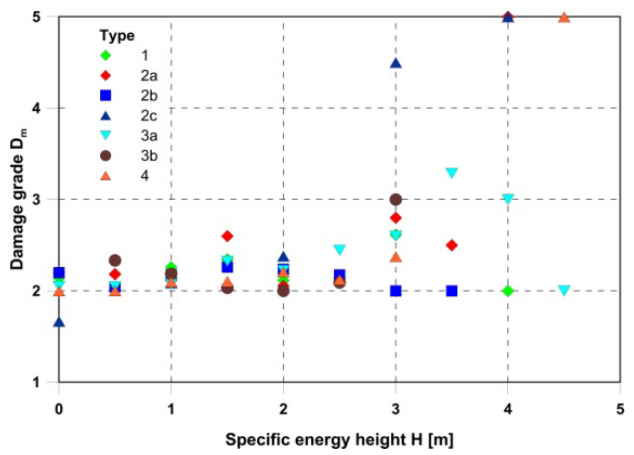

Figure 5: Mean damage $D_{m}$ grades depending on specific energy height $H$, location of building and flow direction [3]. 
The results are shown in Figure 6. Due to the relatively small data density for seve $_{\mathrm{r}}$ al types according to Table 3 , tᄁe results are not explicit in all intervals. However, it can be identified that the structural damage is higher for orthogonally streamed buildings (Type 1, 2a, 2c with the exception of Type $3 \mathrm{~b}$ ) than for tangential streamed buildings like Type $3 \mathrm{a}$ or Type $2 \mathrm{~b}$ at the end of a row of houses. Further investigations on a more comprehensive dataset are necessary.

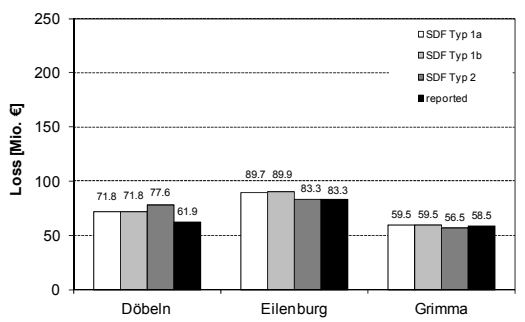

a) Residential buildings

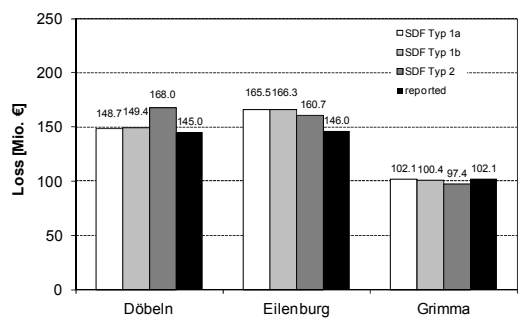

b) Entire building stock

Figure 6: Comparison between calculated and reported losses.

\subsection{Specific damage functions (SDF) - loss prediction}

Following the proposed methodology, a set of rather new types of Specific Damage Functions (SDF) for loss predictions were presented in [2, 3]. Functions refer to the building type (SDF Type 1a) or flood vulnerability class (SDF Type 1b). A second type of functions (SDF Type 2) transfers the calculated damage grades $\mathrm{D}_{\mathrm{i}}$ (see Table 1) into loss statements.

All of the developed functions consider the number of stories and the presence of a basement [6]. The mathematical background of the different types of vulnerability functions is based on an exponential approach and is outlined in $[2,3,10]$. The parameters could be taken from [2].

\section{Case studies}

The innovative options and advantages of the whole procedure are demonstrated by the case studies from the 2002 flood in Saxony. With the developed specific vulnerability functions, the mean damage grade $D_{m}$ can be calculated for each individual building (micro-scale level) in the three study areas Döbeln, Eilenburg and Grimma. In [2, 3], it can be shown how heavily the areas of a community will be affected and where significant damage concentrations are expected. With the different types of damage functions, loss statements are available for the study areas. For the re-interpretation with regard to the water level as the action side, damage functions SDF type $1 \mathrm{a}$ and $1 \mathrm{~b}$ will be used. 
In a third calculation variant, first the mean damage grades $D_{m}$ with vulnerability functions SFV type $2 b$ (with consideration of the flow velocity) are calculated.

These are then converted with damage functions SDF type 2 into loss statements. Despite the different flooding characteristics in the study areas, the comparison of calculation results with the official damage statistics of the Saxon Relief Bank (SAB) shows a very good agreement for the residential building stock (Figure 4a) for all the calculation variants. The slightly higher calculated losses in Döbeln are due to the fact that in the data accumulated in the SAB, not all damage cases are considered. For the prediction of the damage on the entire building stock (Figure 4b), it is taken into account that the application of the damage functions on non-residential buildings is only an approximation.

\section{Photo credits}

The pictures in Table 1 and 2 were made by the Earthquake Damage Analysis Center (EDAC) at the Bauhaus Universität Weimar.

\section{References}

[1] Earthquake Damage Analysis Center, EDAC-Flood Damage Model, http://www.edac.biz/research/floods/edac_hochwasserschadensmodell.html 2011.

[2] Maiwald, H., Schwarz, J., Ermittlung von Hochwasserschäden unter Berücksichtigung der Bauwerksverletzbarkeit. EDAC-Hochwasserschadensmodell. scientific technical reports 01 (2011), Zentrum für die Ingenieuranalyse von Erdbebenschäden, Universitätsverlag, BauhausUniversität Weimar, 2011.

[3] Maiwald, H., Schwarz, J.: Berücksichtigung der Fließgeschwindigkeit bei Hochwasser-Schadensmodellen, Bautechnik 86 (2009) 9, 550 - 565, 2009.

[4] Schwarz, J., Maiwald, H.: Damage and loss prediction model based on the vulnerability of building types. Proceedings 4th International Symposium on Flood Defence, 6 - 8 May 2008, Toronto, Canada, 2008.

[5] Schwarz, J., Maiwald, H., Gerstberger, A., Quantifizierung der Schäden infolge Hochwassereinwirkung: Fallstudie Eilenburg. Bautechnik 82 (2005) $12,845-856,2005$.

[6] Schwarz, J., Maiwald, H., Berücksichtigung struktureller Schäden unter Hochwassereinwirkung, Bautechnik 84 (2007) 7, 450 - 464, 2007.

[7] Schwarz, J., Maiwald, H., Von der Schadensaufnahme zur Verletzbarkeitsfunktion - ein Ansatz aus den Ingenieurwissenschaften. Abschnitt 9.2 in „Hochwasserschäden - Erfassung, Abschätzung und Vermeidung“. Abschlussbericht des RIMAX-Forschungsprojektes MEDIS: „Methoden zur Erfassung direkter und indirekter Hochwasserschäden”: (Hrsg. Thieken, A. H., Seifert, I., Merz, B.), oekom-Verlag, 2009.

[8] Schwarz, J., Maiwald, H., Ingenieurmäßigen Beschreibung der Schadenserwartung von Gebäuden unter Hochwassereinwirkung. 
Abschlussbericht zum Projekt 24614375 im Auftrag der Landestalsperrenverwaltung des Freistaates Sachsen. Zentrum für die Ingenieuranalyse von Erdbebenschäden, Bauhaus-Universität Weimar, 2009.

[9] Grünthal, G. (ed.), Musson, R., Schwarz, J., Stucchi, M., European Macroseismic Scale 1998. Cahiers de Centre Européen de Géodynamique et de Seismologie, Volume 15, Luxembourg, 1998.

[10] Maiwald, H., Ingenieurmäßige Ermittlung von Hochwasserschadenspotentialen im mikroskaligen Maßstab. Dissertation, Department of Civil Engineering, Bauhaus-Universität Weimar, 2007.

[11] Kreibich, H., Piroth, K., Seifert, I., Maiwald, H., Kunert, U., Schwarz, J., Merz, B., Thieken, A. (2009) Is flow velocity a significant parameter in flood damage modelling? Natural Hazards and Earth System Sciences 5, 1679-1692, 2009. 